\title{
GESTÃO DE PESSOAS E DO CONHECIMENTO COMO DIFERENCIAIS COMPETITIVOS E PRODUTIVOS NAS ORGANIZAÇÕES
}

\author{
PEOPLE AND KNOWLEDGE MANAGEMENT AS COMPETITIVE AND \\ PRODUCTIVE DIFFERENTIALS IN ORGANIZATIONS
}

\begin{abstract}
Camila Freitas De Oliveira - Camilafreitas508@gmail.com Faculdade de Tecnologia de Taquaritinga - Taquaritinga - São Paulo - Brasil

Moacir José Bertaci - Moacir.bertaci@fatectq.edu.br Faculdade de Tecnologia de Taquaritinga - Taquaritinga - São Paulo - Brasil
\end{abstract}

DOI: 10.31510/infa.v18i1.1162

Data de submissão: 17/04/2021

Data do aceite: 09/07/2021

Data da publicação: 30/07/2021

\begin{abstract}
RESUMO
Os estudos sobre Gestão de Pessoas e Gestão do Conhecimento nas organizações apontam os mesmos como fatores decisivos na competitividade no atual mercado globalizado. As condições capacitadoras propiciadas por uma boa gestão de pessoas e gestão do conhecimento, permitem que as organizações tenham ideia de como aumentar a criação e a disseminação do conhecimento a fim de manter a vantagem competitiva. Este trabalho terá como o objetivo conhecer a nova lógica de gestão das pessoas nas organizações em busca do conhecimento e os novos papéis que os trabalhadores assumem nesse contexto como diferencial competitivo. Através de pesquisa bibliográfica foram apresentados os conceitos de gestão de pessoas, gestão do conhecimento, capital intelectual e também exemplos bem sucedidos de uma boa gestão nesse tema. Ao final foi possível constatar que as organizações entendem que a gestão de pessoas quando bem executada torna-se um diferencial competitivo em diversos setores.
\end{abstract}

Palavras-chave: Gestão de Pessoas. Gestão do Conhecimento. Capital Intelectual.

\begin{abstract}
Studies on People Management and Knowledge Management in organizations point to them as decisive factors in competitiveness in the current globalized market. The enabling conditions provided by good people management and knowledge management, allow organizations to have an idea of how to increase the creation and dissemination of knowledge in order to maintain competitive advantage. This work will aim to understand the new logic of people management in organizations in search of knowledge and the new roles that workers
\end{abstract}


assume in this context as a competitive differential. Through bibliographic research, the concepts of people management, knowledge management, intellectual capital and successful examples of good management in this topic were presented. In the end it was possible to verify that the organizations understand that the management of people when well executed becomes a competitive differential in several sectors.

Keywords: People Management. Knowledge Management. Intellectual Capital.

\section{INTRODUÇÃO}

As empresas eram vistas até o final da última década do século $\mathrm{XX}$ como um aglomerado de recursos para gerar produtos e serviços enquanto que, as pessoas que a compunham como fatores passíveis de troca e, o conhecimento apenas como uma condição desejável (REZENDE, 2002). Como decorrência da crescente competitividade, o mundo atual, exige que empresas e indivíduos tenham alguma diferenciação para que sejam e tenham um melhor desempenho que os outros, quer seja no mercado de trabalho, no mundo dos negócios ou na vida pessoal. Sob a ótica do conhecimento surgem novas percepções advindas do avanço tecnológico e das inovações que reduziram a distância entre as empresas e possibilitaram o acesso às novidades e evoluções em qualquer parte do mundo, em todos os setores econômicos e, quase no instante do fato ocorrido (REZENDE, 2002).

Segundo Nonaka (2000, p. 28): "Numa economia onde a única certeza é a incerteza, apenas o conhecimento é fonte segura de vantagem competitiva", mas deve-se destacar que uma das grandes características do conhecimento é o fato dele ser altamente reutilizável e tem como característica de que, quanto mais aproveitado, maior o seu valor (SANTIAGO JÚNIOR, 2002; TOLEDO e LOURES, 2006). Para se tornar uma organização vencedora, ela precisa dar respostas em tempo mais curto e o desafio se torna prever precisamente o ritmo e a amplitude das mudanças de mercado que inevitavelmente acontecerão e, reagir a elas. O que fundamentalmente vai colaborar para o alcance desta excelência ainda segundo o autor, é que deve investir em seu capital humano, seus funcionários.

Ao longo da última década do século XX foi intensa a mudança de comportamento do trabalhador frente ao mercado de trabalho e a sua realização propriamente dita. Tornou-se dramática a realidade daqueles que não tiveram acesso à escolarização em tempo certo e oportunidade de uma formação profissional. Foram excluídos do modelo de desenvolvimento que tem sido implantado. Passou a ser comum um profissional com dois anos de conclusão de 
um curso superior e sem a continuidade de estudos se tornar obsoleto profissionalmente. Sob essa ótica, a educação, especialmente a formação profissional, tornou-se importantíssima nos discursos de todas as áreas, em termos da garantia de crescimento econômico e desenvolvimento social do Brasil (ROGGERO, 2003).

De acordo com Antunes e Martins (2002, p. 52): “O novo rumo da economia encontra-se fundamentado em ideias". O número de pessoas engajadas no processo de pesquisa, criando técnicas, materializando ideias, desenvolvendo novas oportunidades de negócios, tende a superar o número de pessoas que estarão trabalhando diretamente na produção física. Isso tornará essencial que se realizem profundas modificações na estrutura e na administração das empresas para que continuem competitivas, mas o conhecimento só gerará valor para uma entidade se esta puder ter contado com os novos conhecimentos produzidos e ser acessada de forma que isso possa conduzir a novos conhecimentos (ANTUNES; MARTINS, 2002).

Este trabalho terá como o objetivo conhecer a nova lógica de gestão das pessoas nas organizações em busca do conhecimento e os novos papéis que os trabalhadores assumem nesse contexto como diferencial competitivo.

\section{GESTÃO DE PESSOAS}

A Gestão de Pessoas, de acordo com França (2007) está relacionada com os mais variados espaços organizacionais como: novas tecnologias, reduções ou novas posições no quadro de funcionários da empresa, contratação incluindo recrutamento e seleção de pessoas, treinamento e desenvolvimento, remuneração e benefícios, banco de talentos, segurança, saúde e qualidade de vida, comunicação com empregados, engenharia de produção e ergonomia, sistemas de gestão da qualidade, inovação tecnológica, desenvolvimento sustentável ou marketing social, competências integrada aos aspectos socioeconômicos e pessoais.

Desde os anos 90 a Gestão de Pessoas adquiriu um contexto estratégico, já que passou a vincular suas práticas à estratégia empresarial e é exercida por gerentes de linha para que Apliquem as devidas estratégias nesse setor". Nesse sentido, definiu-se gestão estratégica de pessoas como "um conjunto de práticas ou missão, políticas e processos da gestão, característicos das organizações nesta era de competitividade”. (Leone, 2007, p. 165). 


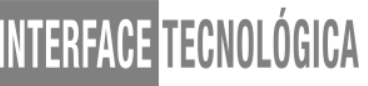

portanto, no contexto dos novos modelos de gestão, as funções clássicas de RH passam a ter as seguintes características:

* Planejamento: as mudanças passam pelo processo de integrar a área de RH ao processo de definição da competência essencial das organizações e do perfil de competência gerencial (Castro e Brito, 2016). Passa primeiramente pela definição da missão, negócio, intenções estratégicas e visão de futuro, depois se preocupa com a formação de líderes comprometidos com o processo de mudança capaz de desenvolver a competências dos trabalhadores e obter deles o comprometimento com a busca de soluções para os problemas empresariais emergentes.

* Suprimento: tratava dos processos de recrutamento e seleção que em sua forma clássica levavam em consideração o conhecimento formal e a experiência das pessoas que ascendiam nas organizações em cargos especializados e em postos fixos de trabalho novo contexto o suprimento é orientado pelo Perfil de Competência Profissional, ou seja, orientado pela construção do perfil de competência para os trabalhadores e os amplos espaços organizacionais que atuarão com foco no mercado e em times de aprendizagem por projetos com liderança compartilhada, estruturas enxutas, processuais em rede e virtuais para aplicar conhecimentos e atitudes que se referem ao querer fazer e o saber fazer (CASTRO;BRITO, 2016).

* Aplicação: construir as referências culturais da organização para o trabalhador quanto ao posicionamento dentro de um espaço organizacional e plano de carreira. Nesse contexto os cargos especializados são substituídos por espaços organizacionais, interdisciplinares e multiprofissionais. É construída uma flexibilidade favorável à mobilização do trabalhador para as áreas e tarefas em que ele possa agregar mais valor e atender as necessidades da organização.

* Treinamento e desenvolvimento: anteriormente o processo era focado no indivíduo, cargo, tarefa e atualmente o foco está no desenvolvimento das competências profissionais. Os trabalhadores não ditam mais suas necessidades de capacitação em listas, ou mesmo solicitam suas capacitações conforme sentem que precisam através de check lists, pois a organização através do "Perfil de Competências Profissionais" traçado é quem direciona a capacitação dos trabalhadores (MUNDIM;RICARDO, 2004).

* Manutenção: anteriormente a remuneração festava focada no cargo, nesse novo contexto tem-se "Planos de Remuneração Estratégica" onde a remuneração variável está focada nos 


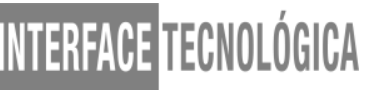

resultados, bem como recompensa para os trabalhadores mais fieis e que agregaram mais valor para as organizações. Agora existem programas internos de premiação por desenvolvimento de novos produtos, serviços, estratégias de gestão que incentivam a inovação e o "empreendedorismo" dos trabalhadores como uma forma de agregar capital e propriedade intelectual para as organizações (MUNDIM;RICARDO, 2004).

* Controle: tradicionalmente era exercido pelo chefe e se restringia a anotação de dados de cada colaborador. $\mathrm{O}$ advento da tecnologia possibilitou uma grande mudança em que um processo integrado permeia todo o processo de gestão de pessoas, ou seja, todos controlam todos apoiados por tecnologias avançadas. Nesse contexto, emergem novos cargos como o de gestor do conhecimento que passa a ter como característica ser um incentivador da criação do conhecimento, da disseminação, contribuição, da avaliação e da filtragem do conhecimento realmente necessário para a organização (CASTRO;BRITO;VARELA, 2017).

\subsection{Conhecimento e competência como diferencial competitivo}

A competência, segundo Fleury e Fleury (2001), está conceituada como um conjunto de habilidades humanas que podem justificar um alto desempenho fundamentado na inteligência e personalidade das pessoas como um estoque de recursos que o indivíduo detém. Sendo assim, se faz necessário alinhar as competências com as necessidades das organizações.

De acordo com Calvosa e Alvarenga (2010), a competitividade que a empresa apresenta ao ambiente externo é condicionada pelo nível de desenvolvimento de sua competitividade interna que resulta de um processo de gestão que mobiliza a inteligência e o conhecimento organizacional para que a empresa se desenvolva e se aperfeiçoe continuamente. Essa busca vai além de bom desempenho e bons resultados. As empresas necessitam adquirir excelência. $\mathrm{O}$ autor ressalta que essa excelência só é obtida quando os gerentes conseguem que as pessoas reproduzam e multipliquem as rotinas de serviço com o objetivo de melhorar a qualificação dos colaboradores, a replicação eficaz de processos produtivos e a gestão do conhecimento e de tecnologia em níveis excelente, empregando o mínimo de recursos possíveis e obtendo o máximo resultado esperado.

Pelissari (2002) afirma que “o ambiente global dos negócios, dinâmico e extremamente competitivo, exige das empresas, independente do porte, maior agilidade nas 
decisões, racionalização de custos, flexibilidade e eficiência operacional”. Segundo o autor, a qualificação do empresário, aliada a informação - rápida e precisa - tem papel fundamental na cadeia de valor das empresas, onde as decisões permitam um gerenciamento mais eficaz e eficiente, antecipando-se às mudanças provocadas pela dinâmica do mercado atual. Diante desse cenário as questões: Ser competitivo ou perecer? Ser diferente ou desaparecer? Como atingir essas ideias? Se a resposta for ser diferente, competitivo é, sem dúvida alguma através da qualificação e capacitação das pessoas e que estas sejam motivadas e autônomas, capazes de decidir, ter iniciativa e assumir uma posição de liderança, como membros de uma equipe solidária (PELISSARI, 2002).

Mattos (2010) afirma que o sucesso ou fracasso organizacional muitas vezes dependerá de sua estratégica e de elementos que perdurem a vantagem no mercado, como: conhecimento, diferenciação na fabricação e inovação tecnológica.

A literatura tem destacado o papel do capital intelectual como principal agente de agregação de valor para aquelas organizações que evidenciam, mensuram e gerenciam o Capital Intelectual de forma efetiva para obter uma vantagem competitiva, uma vez que conseguem identificar todos os ativos à sua disposição (tangíveis e intangíveis), estando, portanto, em condições de fazer uso máximo de seu potencial (CARVALHO, 2006).

\subsection{Gestão do Conhecimento}

O conhecimento envolvido nas atividades organizacionais já tem sido abordado desde as primeiras teorias da administração, ao menos indiretamente. Mesmo antes da revolução industrial, com a produção artesanal nas oficinas já fazia intenso uso da aprendizagem pela prática, por meio da transferência de conhecimentos entre mestres e aprendizes. (SILVA, 2004). O mesmo autor relata que nos anos 80, esse tema tornou-se mais presente com as abordagens teóricas relacionadas à sociedade do conhecimento, ao aprendizado organizacional e às competências essenciais na gestão estratégica. A implantação coordenada da Gestão do Conhecimento-GC cria uma vantagem competitiva sustentável e difícil de ser imitada, pois tem suas raízes nas pessoas que trabalham na empresa, e não em recursos físicos, que são facilmente imitáveis pelos concorrentes e, menos flexíveis para reagir às incertezas do ambiente.

Vasconcelos (2001) argumenta que a gestão do conhecimento envolve a determinação 


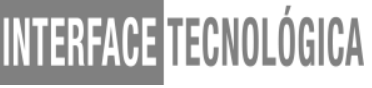

do que a empresa sabe ou deveria saber para alcançar seus objetivos estratégicos. Nessa perspectiva, o conhecimento é visto como um ativo da empresa que deve ser otimizado. Podese dizer que cada vez mais as empresas competirão entre si e se diferenciarão com base naquilo que sabem. Essa visão do conhecimento como um ativo a ser utilizado em situações competitivas mostra que o conhecimento coletivo da organização é uma das características da gestão do conhecimento e, não no conhecimento individual dos funcionários que a compõe. $\mathrm{O}$ trabalho e conhecimento não são facilmente fragmentados em conhecimento de indivíduos isolados, mas insistentemente permanecem propriedades de grupo. $\mathrm{O}$ autor afirma que a criação de valor para o cliente e a melhoria de sua satisfação por meio da criação de produtos e serviços radicalmente inovadores tão importantes para a competitividade na atualidade, dependem não apenas da avaliação de variáveis conhecidas mas também da redefinição e da reinterpretação das variáveis fundamentais - e talvez da descoberta de novos aspectos não antes considerados.

Spender (2001) relata que os gerentes atuais estão conscientes de que o conhecimento e as habilidades da empresa impulsionam suas chances competitivas e que há pouca diferença entre o capital humano que vai para casa à noite e o que se torna disponível mediante as alianças estratégicas. Já é percebido pelos gerentes das empresas que, diante das incertezas proporcionadas pela acirrada concorrência, as oportunidades dela crescem com a extensão, a

profundidade e o escopo do conhecimento e das suas habilidades. É vital que a empresa se reconheça em qual negócio ela está, suas características, em que se baseiam suas potencialidades, forças, fraquezas e capacidade de solucionar riscos advindos de sua dependência de ações externas. A gestão do conhecimento afeta o homem e suas relações com o trabalho, estimulando a globalização e o desenvolvimento da economia que passa a ser um problema mundial, e não mais um problema de um ou de outro país.

O homem hoje é dependente das novas tecnologias da informação e da comunicação, por mais que ele não saiba nem mesmo usar um computador. Quem tem maior acesso à informação, tem maior probabilidade de produzir mais e melhor, e de colher os benefícios decorrentes. O trabalho, antes visto como meio de vida, tende a ser considerado um modo de vida, pois o trabalhador do conhecimento é o proprietário da principal ferramenta de trabalho: o conhecimento (MORAES, 2005). 


\subsection{Casos bem sucedidos de Gestão de Pessoas}

Lobo (2020) apresenta cinco casos famosos de empresas que implantaram uma boa gestão de pessoas:

- Dell: empresa que investe em soluções tecnológicas, como hardwares, servidores e softwares de segurança, entre outros. No entanto, ela tem se destacado também em iniciativas que disseminam o respeito ao colaborador. A empresa investe na promoção do apoio à diversidade e à inclusão criando comunidades para debater temas que possibilitam a conexão entre diferentes pessoas da mesma equipe. É uma gestão eficaz porque os colaboradores podem encontrar apoio, aconselhamentos e dicas profissionais dentro de seu ambiente de trabalho, além de se sentirem respeitados por colegas e chefes, eles se sentem mais à vontade na própria pele. Resultado: aumento de produtividade e de diversidade entre as equipes.

- Airbnb: Conhecida como o maior serviço de hospedagem do mundo, mesmo sem ter nenhum quarto de hotel. Conecta pessoas que precisam de hospedagens com seus anfitriões de inúmeros países. Com base na experiência dos próprios colaboradores dentro da plataforma, a Airbnb criou um ambiente focado no bem-estar, engajamento e felicidade. $\mathrm{O}$ objetivo era envolver questões físicas, emocionais, intelectuais e aspiracionais - tudo isso em horário comercial. É eficaz porque além de ser uma preocupação a mais com o bem-estar do funcionário, o que, por si só, é capaz de gerar um retorno positivo, a empresa ainda faz uma imersão dos colaboradores dentro de seus próprios produtos: casa, novas experiências, viagem ao mundo, etc. Isso tem o potencial de tornar o colaborador um advogado da marca.

- Caterpillar: fabrica máquinas, motores e veículos pesados voltados para a construção civil e mineração. Em 2019, a organização foi eleita a melhor empresa para se trabalhar. Para os funcionários, o objetivo é garantir que o ambiente de trabalho seja diversificado e inclusivo, respeitando as experiências e os pontos de vista de cada um, visando garantir esse compromisso, a organização criou Grupos de Recursos compostos pelos próprios funcionários, fornecendo oportunidades para o desenvolvimento pessoal e profissional e preparando o terreno para ideias inovadoras. Quando a empresa investe na formação e no treinamento de seus integrantes, está investindo na pessoa, no potencial dela, e não diretamente na empresa. Isso pode demonstrar reconhecimento, levando à retenção de talentos - e, claro, melhoria de produtividade, já que uma pessoa bem treinada que ficará só mais dois meses é melhor do que uma que não tem produtividade por estar sem treinamento há quatro. 
- Ford: montadora de veículos, é referência em inovação e gestão de pessoas em grandes empresas, sendo citada como uma das líderes mundiais em práticas de RH. Um dos projetos da empresa é o One Ford Business, série de interfaces tecnológicas usadas pra gerenciar talentos e adaptá-los às constantes mudanças do mercado. Outro programa da Ford é o Dirija seu Futuro com ações de desenvolvimento em que o próprio funcionário define o rumo que ele quer dar para a sua carreira. É eficaz porque empresas como as do mercado automobilístico só são competitivas porque desenvolvem novos produtos com design arrojado, segurança e inovação. Manter uma equipe que acompanhe as demandas dos consumidores - e que esteja sempre um passo à frente das demais - não é só um reconhecimento de RH, mas, também, uma questão de sobrevivência mercadológica.

- FedEx: trabalha com remessa expressa de correspondência, documentos e objetos cria métodos para estimular que todos os funcionários participem ativamente da decisão do negócio. Dessa forma, ela utiliza uma prática bastante comum no meio corporativo: $o$ feedback. Nesta empresa a regra do jogo é inversa: os funcionários avaliam se a gestão da empresa está boa, e não o contrário. Eles também podem se pronunciar livremente sobre pontos de melhoria que precisam ser implementados.

\section{PROCEDIMENTOS METODOLÓGICOS}

Este estudo será exclusivamente pautado pela pesquisa bibliográfica, com o levantamento de informações que compõe a literatura pertinente ao assunto, incluindo estudos de caso publicados que identificam os benefícios da gestão de pessoas e do conhecimento.

Para Lakatos e Marconi (2001, p. 183) a "pesquisa bibliográfica abrange toda bibliografia já tornada pública em relação ao tema de estudo, desde publicações avulsas, boletins, jornais, revistas, livros, pesquisas, monografias, teses, gravações audiovisuais, etc.”, permitindo que o pesquisador entre em contato direto com tudo que diz respeito ao assunto que será estudado. Sua finalidade é de colocar o pesquisador em contato direto com tudo o que foi escrito, dito ou filmado sobre determinado assunto (LAKATOS; MARCONI, 2001).

\section{RESULTADOS E DISCUSSÃO}

Apesar das diferenças de abordagem, as noções de gestão do conhecimento atualmente 
prevalecentes têm um elemento em comum. O conhecimento organizacional é visto como knowhow coletivo da organização, isto é, como o saber envolvido na solução de problemas. Sua expertise, representa a competência expressa no conhecimento que essa organização coletivamente acumulou e nos problemas que ela efetivamente consegue resolver.

Os desafios das organizações segundo Toledo e Loures (2006), passam em como aproveitar, ao máximo todos os talentos individuais (valores intangíveis), através dos seus relacionamentos e da sua valorização. Além do que, as organizações que se baseiam no conhecimento tendem a ter seu valor de mercado muito maior que seu valor patrimonial.

Fleury e Fleury (2001) acrescentam que o conjunto de conhecimentos, habilidades e atitudes, fundamentados na inteligência e personalidade das pessoas é que justificam um alto desempenho. Desta forma, pode-se dizer que o conhecimento e a competência são os fatores que distinguem pessoas e empresas quando se leva em consideração esta competitividade (FLEURY; FLEURY, 2001).

Roggero (2003) ressalta que a educação continuada passou a ser fortemente estimulada e comenta que: "tornou-se senso comum que qualquer profissional que queira garantir sua sobrevivência no mercado de trabalho deve aderir à ideia de manter-se atualizado por meio de um retorno aos sistemas de formação".

A organização segundo Dutra (2002), pode transferir seu patrimônio de conhecimento e experiências para as pessoas, tornando-as enriquecidas e preparadas para enfrentar os desafios pessoais e profissionais.

De acordo com Galhano (2011), as organizações devem atingir resultados satisfatórios pela coordenação de sua estratégia, estrutura organizacional e cultura corporativa, o que significa "adotar uma nova estrutura que permita à organização criar uma nova cultura e gerenciar seus ativos do conhecimento e atingir seus objetivos globais".

\section{CONSIDERAÇÕES FINAIS}

Após pesquisa de artigos e matérias sobre o tema, pode-se dizer que o objetivo deste trabalho foi alcançado. Foi possível comprovar que na competitividade do mundo dos negócios, o conhecimento e a competência são fatores extremamente importantes para qualquer atividade que se queira desenvolver, seja na vida pessoal, profissional ou das empresas. As empresas e as pessoas passam a se dividirem em duas categorias distintas: os 
que têm ou não tem esses atributos. O poder não mais se restringe ao domínio dos meios materiais, mas cada vez mais, a partir do controle sobre o imaterial e o intangível, ou seja na informação e no conhecimento. Fazer a gestão de pessoas adequada em uma organização é tão importante quanto gerenciar o próprio negócio. Afinal, quem faz a empresa crescer, se desenvolver e ser mais competitiva são os próprios funcionários.

Pode-se dizer que a gestão de pessoas define as estratégias que tornam possível melhorar a administração de recursos humanos. É isso que faz com que a capacitação e o desenvolvimento dos funcionários sejam tão importantes para a eficiência das organizações.

\section{REFERÊNCIAS}

ANTUNES, Maria Thereza Pompa; MARTINS Eliseu. Capital intelectual: verdades e mitos. Revista Contabilidade \& Finanças. v. 13 n. 29. São Paulo, 2002.

CALVOSA, Marcello; ALVARENGA, Murilo. Os funcionários percebem a gestão do conhecimento no ambiente de trabalho? Estudo de caso na realidade de uma pequena empresa. Revista UNIABEU Belford Roxo v.3 n.5 p. 203-229. set./dez. 2010.

CARVALHO, Fernando Nitz de; Ensslin, Sandra Rolim. A evidenciação voluntária do Capital Intelectual: um estudo revisionista do contexto internacional. Contabilidade Vista \& Revista, v. 17, n. 4, p. 55-72, out./ dez. 2006.

CASTRO, A. B.C.de, BRITO, L. M. P. Gestão do Conhecimento: como as organizações Públicas do Brasil percebem esse modelo? Revista Gestão Industrial. 12(2), 59-72. 2016.

CAStro, A. B. C. BRITO, L. M. P.; VARELA, J. H. de S. A ressignificação da área de gestão de pessoas e os novos papéis das pessoas e das organizações. HOLOS, vol. 4, 2017, pp. 408-423. Instituto Federal de Educação, Ciência e Tecnologia do Rio Grande do Norte Natal, Brasil.

DUTRA, Joel Souza. Gestão de pessoas: modelos, processos, tendências e perspectivas. 1. ed. São Paulo: Atlas, 2002.

FLEURY, Maria Tereza Leme; FLEURY, Afonso. Construindo o conceito de competência. RAC - Revista de Administração Contemporânea - Edição Especial. p. 183-196, 2001.

FRANÇA, A. C. L. Práticas de Recursos Humanos: conceitos, ferramentas e procedimentos. São Paulo: Atlas.2007.

GALHANO, Patrícia Portela Prado; NAKATA, Lina Eiko. Gestão do Conhecimento em estruturas inovativas: um estudo de caso. Dimens. Empres. v. 9,n.2,p.35-47,jul./dez.2011. Disponível em: http://dialnet.unirioja.es/servlet/articulo?codigo=3965874. Acesso em: 21 jan. 2013. 
LAKATOS, Eva Maria; MARCONI, Marina de Andrade. Fundamentos da metodologia científica. 4. ed. São Paulo: Atlas, 2001.

LASTRES, Helena; Albagli, Sarita. Informação e globalização na era do conhecimento. Rio de Janeiro: Campus, 1999.

LEONARDO, Jeferson Marco Antonio. A guerra do sucesso pelos talentos humanos. Revista Produção. v. 12, n. 2, p. 42-53. 2002. Disponível em: http://www.scielo.br/pdf/prod/v12n2/v12n2a05.pdf. Acesso em: 20 jan. 2013.1

LEONE, N.M. de C. P. G. Evidências empíricas em face das referências teóricas nas funções estratégicas da gestão de pessoas. In: Brito, L. M. P. (Org.). Práticas de pesquisa em gestão de pessoas 2: a tênue separação entre o público e o privado no Brasil. Fortaleza: Edições UFC.2007.

LOBO, Eduardo. 5 casos famosos de boa gestão de pessoas em grandes empresas. QR POINT - Gestão e Sistemas de RH. 4 abr 2020.

Disponível em: https://www.qrpoint.com.br/blog/5-casos-famosos-de-gestao-de-pessoas-emgrandes-empresas/. Acesso em: 02 abr. 2021

MATTOS, Luciano Aparecido de. Gestão estratégica do conhecimento: um estudo de caso. Dissertação (Mestrado). Centro Universitário, Curitiba-PR, 2010.

MORAES, Evelise Quadrado de. Uma introdução sobre gestão do conhecimento. Revista do TCU - Tribunal de Contas da União. ano 35, n.105, p.55-59, jul./set. 2005.

MUNDIM, A.P.F. RICARDO,E.J. Educação Corporativa. Rio de Janeiro: Qualitymark. 2004.

NONAKA, Ikujiro. A empresa criadora de conhecimento. In: Gestão do Conhecimento. 8. ed. Rio de Janeiro: Campus, 2000. p.27-49. (Série Harvard BussinessReview).

PELISSARI, Anderson Soncini. O perfil de qualificação profissional dos empresários das pequenas empresas de confecções da glória - Vila Velha-ES. Dissertação (Mestrado em Engenharia de Produção). Universidade Federal de Santa Catarina, Florianópolis, 2002.

REZENDE, Yara. Informação para negócios: os novos agentes do conhecimento e a gestão do capital intelectual. Ci. Inf., Brasília, v. 31, n. 1, p. 75-83, jan./abr. 2002.

ROGGERO, Rosemary. Qualificação e Competência: um diálogo necessário entre sociologia, gestão e educação para alimentar as práticas pedagógicas na formação profissional. Boletim Técnico do Senac, 2003

SANTIAGO JÚNIOR, José Renato Sátiro. O Desenvolvimento de uma metodologia para gestão do conhecimento em uma empresa de construção civil. 2002.127f.Dissertação (Mestrado) - Escola Politécnica da Universidade de São Paulo. Departamento de Engenharia 
de Produção. São Paulo, 2002.

SILVA, Sérgio Luis da. Gestão do conhecimento: uma revisão crítica orientada pela abordagem da criação do conhecimento. Ci. Inf., Brasília, v. 33, n. 2, p. 143-151, maio/ago. 2004.

SPENDER, J.C. Gerenciando sistemas de conhecimento. In: FLEURY, Maria Tereza Leme. Gestão estratégica do conhecimento. São Paulo: Atlas, 2001. p. 27-49.

TOLEDO, Luciano Augusto; LOURES, Carlos Augusto. Organizações virtuais. Cadernos Ebape.Br. v. 4, n. 2 , jun. 2008

VASCONCELOS, Flávio C. Da gestão do conhecimento à gestão da ignorância: uma visão co-evolucionária. RAE - Revista de Administração de Empresas. São Paulo, v. 41. n. 4. p. 98-102, out./dez. 2001. 